Check for updates

Cite this: Dalton Trans., 2021, 50 16670

\title{
Reduced quenching effect of pyridine ligands in highly luminescent Ln(III) complexes: the role of tertiary amide linkers $\uparrow$
}

\author{
Daniel Kocsi, Daniel Kovacs, Jordann A. L. Wells (D) and K. Eszter Borbas (D)*
}

Luminescent Eu(III) and Tb(III) complexes were synthesised from octadentate ligands carrying various carbostyril sensitizing antennae and two bidentate picolinate donors. Antennae were connected to the metal binding site via tertiary amide linkers. Antennae and donors were assembled on a 1,4,7-triazacyclononane (tacn) platform. Solution- and solid-state structures were comparable to those of previously reported complexes with tacn architectures, with nine-coordinate distorted tricapped trigonal prismatic Ln(III) centres, and distinct from those based on 1,4,7,10-tetraazacyclododecane (cyclen) macrocycles. In contrast, the photophysical properties of these tertiary amide tacn-based complexes were more comparable to those of previously reported systems with cyclen ligands, showing efficient Eu(II) and Tb(III) luminescence. This represents an improvement over secondary amide-linked analogues, and is due to a greatly increased sensitization efficiency in the tertiary amide-linked complexes. Tertiary amide-linked Eu(III) and $\mathrm{Tb}(\mathrm{III})$ emitters were more photostable than their secondary amide-linked analogues due to the suppression of photoinduced electron transfer and back energy transfer.

Received 28th August 2021, Accepted 26th October 2021 DOI: $10.1039 / \mathrm{d} 1 \mathrm{dt} 02893 \mathrm{f}$ rsc.li/dalton octa-, and nonadentate ligands can be constructed from tetraand triazamacrocyclic (cyclen and tacn, respectively, Fig. 1) building blocks upon the addition of mono- and bidentate donors, e.g. carboxylates, carbamides, or picolinates. ${ }^{32}$ While the primary role of the ligand is to create a well-defined, stable emitter, it has additional functions. Ln(III) luminescence is sensitive to nearby $\mathrm{X}-\mathrm{H}$ oscillators. ${ }^{3,33}$ While $\mathrm{X}$ can be $\mathrm{O}, \mathrm{N}$ or, in the case of near infrared emitters, even $\mathrm{C}$, the largest quenching effect is due to inner-sphere $\mathrm{O}-\mathrm{H}$-containing solvent molecules, such as water or $\mathrm{MeOH} .{ }^{34,35}$ A high-denticity ligand can displace most inner-sphere solvent molecules, and thus improve Ln(III) luminescence.

A further role of the ligand is to impose a coordination geometry. The shielded 4f-orbitals do not participate in directional bonding, and Lns bind preferentially hard donor atoms (such as $\mathrm{O}, \mathrm{F})$ through coulombic interactions. The ligand can thus determine the symmetry around the Ln(III), which in turn will govern the radiative lifetime $\left(\tau_{\text {rad }}\right)$ of the ion. The overall luminescence quantum yield $\left(\Phi_{\mathrm{Ln}}\right)$ is the product of the efficiency with which the $\operatorname{Ln}(\mathrm{III})$ excited state is populated $\left(\eta_{\text {sens }}\right)$ via absorption, intersystem crossing, energy transfer, etc., and the intrinsic quantum yield $\left(\Phi_{\mathrm{Ln}}^{\mathrm{Ln}}\right)$ of the ion (eqn (1)). The latter is equal to the proportion of observed $\left(\tau_{\mathrm{obs}}\right)$ and radiative lifetimes. ${ }^{36,37}$ All else being equal, shorter $\tau_{\text {rad }}$ yields higher $\Phi_{\mathrm{Ln}}$.

$$
\Phi_{\mathrm{Ln}}=\eta_{\mathrm{sens}} \cdot \Phi_{\mathrm{Ln}}^{\mathrm{Ln}}=\eta_{\mathrm{sens}} \cdot \frac{\tau_{\mathrm{obs}}}{\tau_{\mathrm{rad}}}
$$




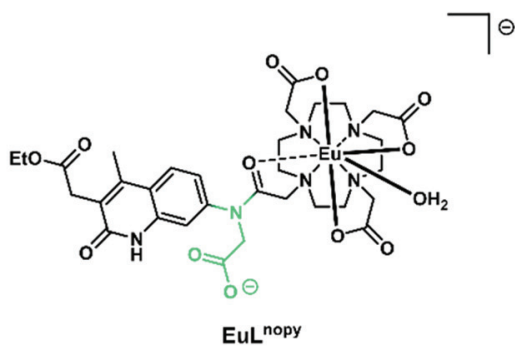

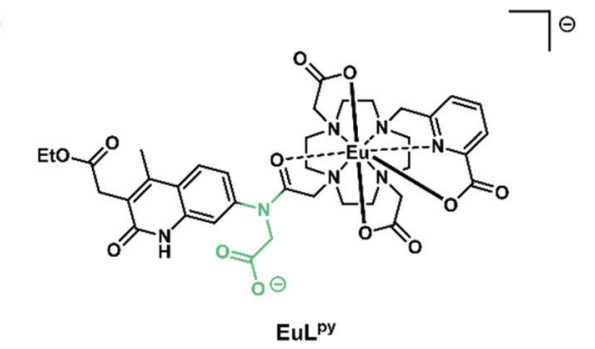

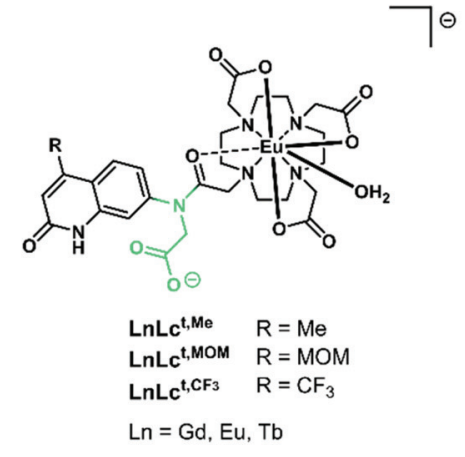

\rceil$^{\ominus}$
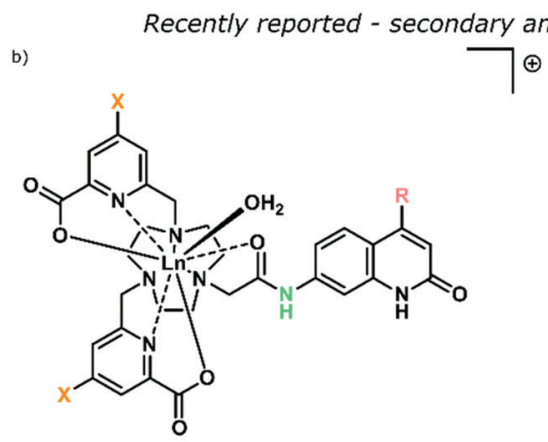

\begin{abstract}
core
\end{abstract}

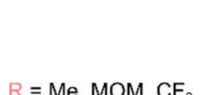

$\mathrm{X}=\mathrm{OMe}, \mathrm{H}, \mathrm{Cl}, \mathrm{CF}_{3}$ $\mathrm{Ln}=\mathrm{Gd}, \mathrm{Eu}, \mathrm{Tb}$

For $\mathrm{X}=\mathrm{H}$

LnLt ${ }^{\mathrm{s}, \mathrm{Me}}$

LnLt ${ }^{\mathrm{s}, \mathrm{MOM}}$

LnLt $^{\text {s, CF3 }}$

EuLpy

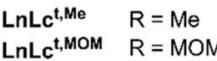

$\mathrm{Ln}=\mathrm{Gd}, \mathrm{Eu}, \mathrm{Tb}$
This work - tertiary amide linker

c)

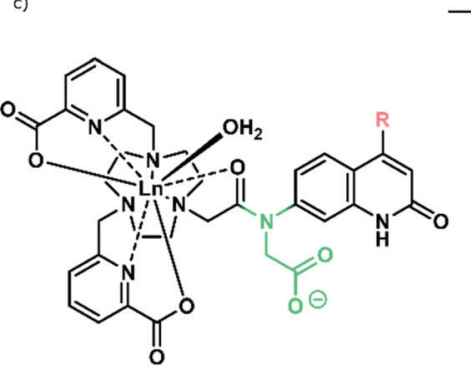

LnLt, Me $\quad R=M e$

LnLt, MOM $R=$ MOM

LnLt ${ }^{\mathrm{t}, \mathrm{CF} 3} \quad \mathrm{R}=\mathrm{CF}_{3}$

$\mathrm{Ln}=\mathrm{Gd}, \mathrm{Eu}, \mathrm{Tb}$

Fig. 1 (a) Previously reported tertiary amide-linked complexes with carbostyril antennae, ${ }^{39}$ including cyclen-based benchmarks LnLc $^{\mathrm{t}, \mathrm{R}}$. $^{42}$ (b) Secondary amide-linked carbostyril-sensitised $\mathrm{LnLt}^{\mathrm{s}, \mathrm{R}}$ consisting of a tacn ligand framework equipped with substituted picolinic acid donors. ${ }^{38}$ (c) LnLt ${ }^{\mathrm{t}, \mathrm{R}}$ complexes studied here.

We have previously prepared both tacn and cyclen-based complexes with a variety of carbostyril and coumarin antennae (Fig. 1). Notably, the Eu(III) complexes of the octadentate tacnbased ligands $\left(\mathbf{L n L t}^{\mathbf{s}, \mathbf{R}}\right)$ had much shorter $\tau_{\text {rad }}(\sim 3 \mathrm{~ms})^{38}$ than those of their similarly octadentate cyclen-based analogues (e.g. $\left.\mathbf{L n L c} \mathbf{c}^{\mathbf{s}, \mathbf{R}}, \tau_{\mathrm{rad}} \sim 5 \mathrm{~ms}\right){ }^{39-42}$

Ligands can control quenching processes other than $\mathrm{X}-\mathrm{H}$ quenching. Photoinduced electron transfer (PeT) whereby the excited antenna reduces $\mathrm{Ln}$ (III) to $\mathrm{Ln}$ (II) is common in emitters with reducible $\mathrm{Ln}(\mathrm{III})$, such as Eu. ${ }^{43,44}$ The re-oxidation of $\mathrm{Eu}(\mathrm{II})$ usually yields a quenched complex, although exceptions are known. ${ }^{45,46}$ The detrimental effects of PeT in some systems is comparable to that of $\mathrm{X}-\mathrm{H}$ oscillators. ${ }^{40}$ Ligands that stabilise the $\mathrm{Eu}(\mathrm{III})$ oxidation state can increase the luminescence quantum yield. ${ }^{40}$ The ligand may also directly quench the excited antenna. ${ }^{39}$ This is the case in the picolinate-equipped $\mathbf{L n L t}^{\mathbf{s}, \mathbf{R}}$ (Fig. 1), where the electron-poor pyridines are reduced alongside Eu(III) by the photoexcited antenna. PeT to the pyridines was possible even in the non redox-active $\mathrm{Tb}$ (III) and $\mathrm{Gd}(\mathrm{III})$, and was more prominent for electron-poor pyridines. ${ }^{38}$

Here, we report a series of tacn-based ligands and their $\mathrm{Ln}$ (III) complexes equipped with the same picolinate ligands that were previously shown to be detrimental to Ln(III) luminescence (Fig. 1). We show that changing the linker that connects the carbostyril antenna to the tacn fragment from a secondary $\left(\mathbf{L n L t} t^{\mathbf{s}, \mathbf{R}}\right)$ to a tertiary amide $\left(\mathbf{L n L t} t^{\mathbf{t}, \mathbf{R}}\right)$ can result in the recovery of Ln(III) luminescence, and afford emitters that are compar- able to what was seen in cyclen-based systems. The complexes were structurally characterised by paramagnetic ${ }^{1} \mathrm{H}$ NMR spectroscopy and X-ray crystallography to enable comparison of the Ln(III) coordination environments in the secondary and tertiary amide-linked complexes. Steady-state and time-resolved luminescence spectroscopy was used to understand the sensitization and quenching pathways in these emitters, and revealed a significantly improved sensitization in the new set of picolinate-containing species compared to the previously reported ones. These results indicate that even efficient quenching processes can be interrupted by judiciously chosen structural changes.

\section{Results and discussion}

\section{Synthetic procedures}

The ligands $\mathbf{L} \mathbf{t}^{\mathbf{t}, \mathbf{R}}$ were synthesised from 4-methyl-, 4-methoxymethyl- or 4-trifluoromethyl-substituted 7-aminocarbostyrils $\mathbf{1 a}, \mathbf{1 b}$ and $\mathbf{1 c}$, via the tertiary chloroacetylamides $\mathbf{2 a}, \mathbf{2 b}$, and 2c, respectively (Scheme 1). The latter were prepared similarly to their tert-butyl ester analogues. ${ }^{38}$ Di-substituted triazanonane $\mathbf{3}$ was monoalkylated with $\mathbf{2 a - c}$ to yield protected ligands 4a-c, which were deprotected under basic conditions. Heating $\mathbf{L t}{ }^{\mathbf{t}, \mathbf{R}}$ with $\mathbf{L n C l}_{3}$ in a warm EtOH : $\mathrm{H}_{2} \mathrm{O}$ mixture yielded $\mathbf{L n L} \mathbf{t}^{\mathbf{t}, \mathbf{R}}$ after column chromatography on silica gel using ${ }^{\mathrm{i}} \mathrm{PrOH}: \mathrm{H}_{2} \mathrm{O}$ as the eluent in quantitative yield as white solids. Detailed 


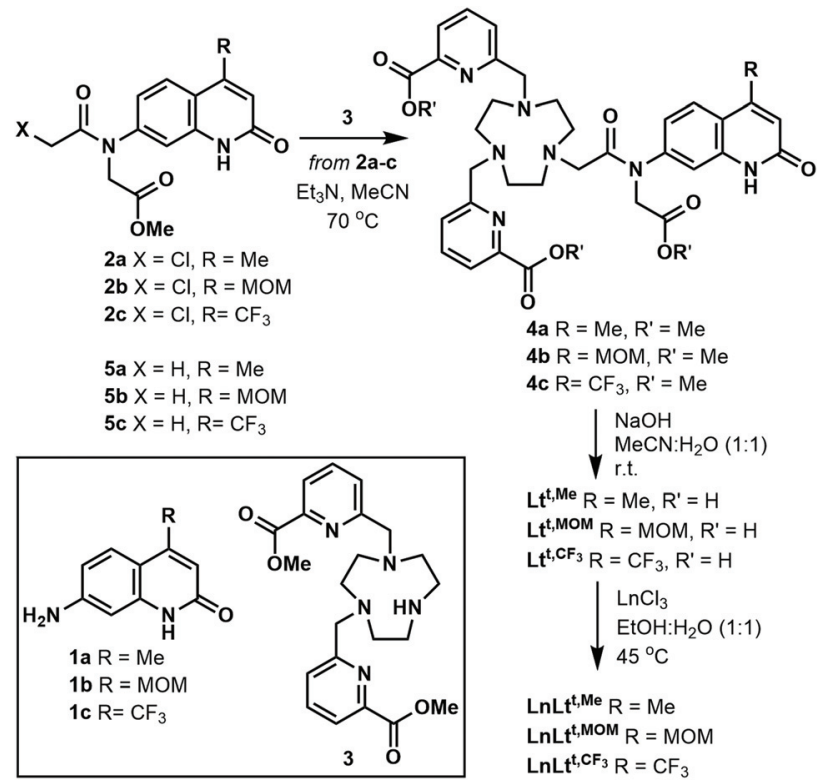

Scheme 1 Preparation of $\mathrm{LnLt}^{\mathrm{t}, \mathrm{R}}$ and model compounds $5 \mathrm{a}-\mathrm{c}$.

experimental procedures and full chemical characterization for all new compounds are given in the ESI. $\dagger$

\section{X-ray crystallography}

Single crystals suitable for X-ray diffraction analysis were obtained by vapor diffusion of glyme into concentrated aqueous solutions of $\mathbf{G d L t}^{\mathrm{t}, \mathbf{M e}}$ and $\mathbf{T b L t} \mathbf{t}^{\mathrm{t}, \mathbf{M e}}$. The presence of the carboxylate group on the amide functionality of the ligand results in a coordination motif not seen for related complexes containing secondary amides. ${ }^{38}$ The carboxylate group acts as a bridging ligand between LnLt molecules, forming 1D-polymeric chains. In addition, a secondary Ln centre is coordinated to a pyridine carboxylate $\mathrm{C}=\mathrm{O}$ bond, acting as a bridge between $1 \mathrm{D}$-polymeric chains resulting in a $2 \mathrm{D}$-polymeric network (Fig. 2).

The Ln centre within the macrocylic cavity exhibits a ninecoordinate distorted tricapped trigonal prismatic geometry, comparable to that observed in related complexes. The trigonal prism is represented by three tacn $\mathrm{N}$-donor atoms $\left(\mathrm{N}_{3 \mathrm{PL}}\right)$, and two pyridine $\mathrm{N}$ - and the antenna amide $\mathrm{O}$-atoms $\left(\mathrm{NNO}_{\mathrm{PL}}\right)$. The pyridine carboxylate groups and the bridging carboxylate arm of the tertiary amide serve as the capping ligands of the trigonal prism. The angle between the two planes is $115.1(3)^{\circ}$ in $\mathrm{Gd}$ and $116.8(6)^{\circ}$ in $\mathrm{Tb}$, which compares well to those of related complexes. The deviation of the angle from $180^{\circ}$ can be ascribed to the highly distorted geometry of the metal centre. The distance between the Ln centres and the $\mathrm{NNO}_{\mathrm{PL}}$ are comparable to those of the corresponding secondary amide complexes $(0.312(3)$ and $0.328(6) \AA$ for Gd and Tb, respectively, versus average $0.312 \AA$ ), as are the distances to the $\mathrm{N}_{3 \mathrm{PL}}$ (Gd:

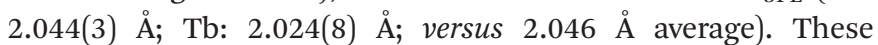
metrics suggest that the tertiary amide group and the carboxylate bridging ligand have no significant impact on the direct

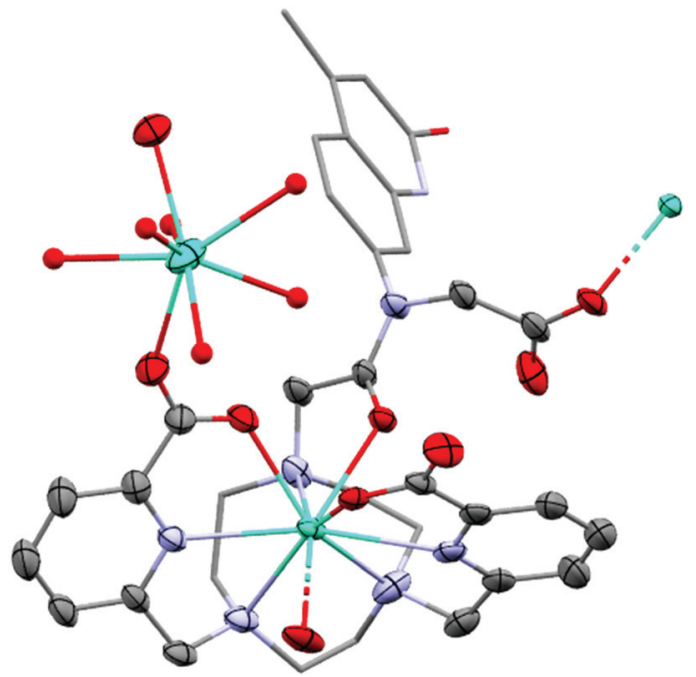

Fig. 2 Solid-state structures of $\mathrm{TbLt}^{\mathrm{t}, \mathrm{Me}}$. $\mathrm{H}$ atoms, non-coordinating $\mathrm{Cl}^{-}$ counterions and water molecules omitted, triazacyclonane $\mathrm{C}$ atoms and antenna displayed as capped sticks and Ln2 co-ligands displayed as ball and stick for clarity. Ellipsoids displayed at 35\% probability. Only major component of disordered sites displayed.

coordination sphere of carbostyril-substituted tacn systems. The complexes are racemic in the solid-state with both $\Delta$ and $\Lambda$ isomers present in the unit cell. The Ln-O (Gd: 2.388(4) $\AA$; Tb: 2.376(6) ̊), tacn Ln-N (Gd: 2.646(4) ̊; Tb: 2.64(1) ̊) and pyridine Ln-N (Gd: 2.548(6) ̊; Tb: 2.538(8) ̊̊) bond distances compare well to those of related complexes.

The secondary Ln centre is eight-coordinate and exhibits a square antiprismatic arrangement. Two picolinate carbonyl groups occupy flanking positions, while the remaining six sites are occupied by water ligands, and the charge balancing chloride counter-ions are non-coordinated and reside in the crystal lattice. The metal centre at this position is partially occupied $(75 \%)$, which results in considerably disordered lanthanide bound ligands and imprecise bond lengths, which are not discussed here (see ESI $\dagger$ for further information).

\section{NMR studies}

Paramagnetic ${ }^{1} \mathrm{H}$ and ${ }^{19} \mathrm{~F}$ NMR spectroscopic analysis of EuLt ${ }^{\mathrm{s}}$ and $\mathbf{E u L t}^{\mathrm{t}}$ was performed in $\mathrm{D}_{2} \mathrm{O}$. Complexes with identical metal-binding sites had similar spectra (Fig. 3). At r.t. the signals were broad and indicative of the presence of several species that made the comparison of the data difficult. However, good quality spectra were obtained in all cases upon heating the samples at $80^{\circ} \mathrm{C}$. At high temperature the ${ }^{1} \mathrm{H}$ NMR spectra of the EuLt ${ }^{\mathrm{s}}$ species contained $\sim 15$ signals, consistent with the presence of a single species or of several species rapidly interconverting on the NMR timescale (Fig. S3-18†). The spectra of $\mathbf{E u L t}^{\mathbf{t}}$ were much sharper than those of the corresponding EuLt ${ }^{\mathrm{s}}$ even at room temperature, and further improved upon heating. The $80^{\circ} \mathrm{C}$-spectra of EuLt $\mathbf{t}^{\mathrm{t}}$ contained two sets of signals, which suggests that there are two stable conformers in the solution even at high temperatures. These 
a)

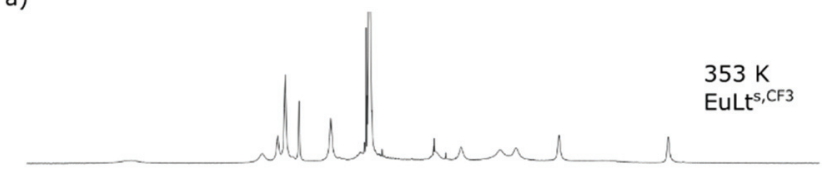

b)

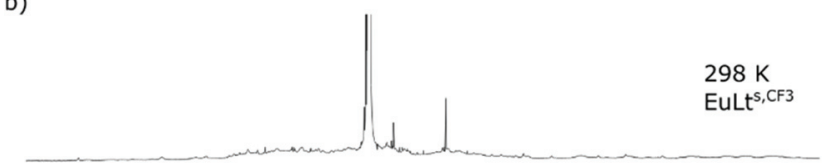

c)

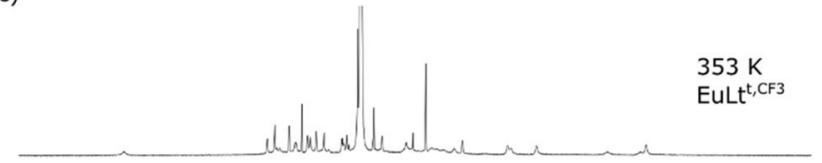

d)

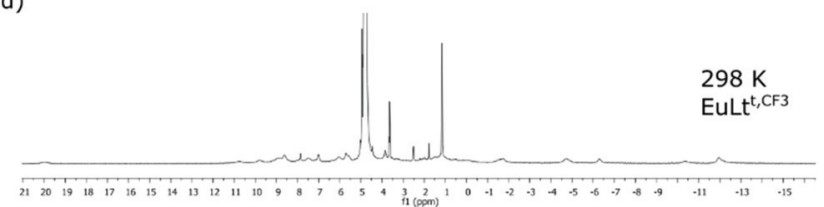

Fig. 3 Variable temperature ${ }^{1} \mathrm{H}$ NMR spectra recorded in $\mathrm{D}_{2} \mathrm{O}$. (a) EuLt $^{\text {s,CF3 }}$ at 353 K. (b) EuLt ${ }^{\text {s,CF3 }}$ at 298 K. (c) EuLt ${ }^{\text {t,CF3 }}$ at 353 K. (d) EuLt $^{\mathrm{t}, \mathrm{CF} 3}$ at $298 \mathrm{~K}$.

conclusions were supported by the ${ }^{19} \mathrm{~F}$ NMR analysis of $\mathbf{E u L t}^{\mathbf{s}, \mathbf{C F} 3}$ and $\mathbf{E u L t}^{\mathrm{t}, \mathbf{C F 3}}$. At r.t. a large number of signals were observed for $\mathbf{E u L t}^{\mathbf{s}, \mathbf{C F} 3}$, and a broadened peak consisting of several peaks for $\mathbf{E u L t}^{\mathbf{t}, \mathbf{C F} 3}$. In line with the ${ }^{1} \mathrm{H}$ NMR data, at $80{ }^{\circ} \mathrm{C}$ the signals collapsed into a single peak (-61.9 ppm), while that of $\mathbf{E u L t}^{\mathrm{t}, \mathbf{C F} 3}$ into one major and two minor ones (around -62.7 ppm) (Fig. S11-18†).

\section{Photophysical studies}

The photophysical properties of $\mathbf{L n L t}^{\mathbf{t}, \mathbf{R}}$ were measured under the same conditions as those of $\mathbf{L n L t}^{\mathbf{s}, \mathbf{R}}$ and $\mathbf{L n L} \mathbf{c}^{\mathbf{t}, \mathbf{R}, 38,42}$ in PIPES-buffered $\mathrm{pH}=6.5$ aqueous solution at $\mathrm{r}$. $\mathrm{t}$. The $\mathbf{L n L t}^{\mathbf{t}, \mathbf{R}}$ absorption spectra contained peaks in the $250-310 \mathrm{~nm}$ region that were absent from the spectra of $\mathbf{L n L} \mathbf{c}^{\mathbf{t}, \mathbf{R}}$, but were present in $\mathbf{L n L t}^{\mathbf{S}, \mathbf{R}}$ (Fig. 4, S22-27†). These peaks were assigned to pyridine $\pi-\pi^{*}$ transitions. The longest-wavelength absorption was determined by the antenna (Table 1 ), and the position of the maxima increased in the order $\mathbf{L n L t}^{\mathbf{t}, \mathbf{M e}}\left(\lambda_{\mathrm{abs}}=325 \mathrm{~nm}\right)<$ $\mathbf{L n L t}^{\mathbf{t}, \mathbf{M O M}}\left(\lambda_{\mathrm{abs}}=328 \mathrm{~nm}\right)<\mathbf{L n L t}^{\mathbf{t}, \mathbf{C F} 3}\left(\lambda_{\mathrm{abs}}=338 \mathrm{~nm}\right)$. Upon antenna excitation weak antenna fluorescence was observed at $\lambda_{\text {em }}=366-391 \mathrm{~nm}$; longer emission wavelengths were seen for the more red-absorbing antennae. While $\lambda_{\mathrm{abs}}$ for $\mathbf{L n L t}{ }^{\mathrm{t}, \mathbf{R}}$ were at wavelengths that were 3-4 $\mathrm{nm}$ shorter than seen for the corresponding $\mathbf{L n L t}^{\mathbf{s}, \mathbf{R}}$, this small difference all but disappeared in the emission spectra.

The antenna first triplet excited states $\left(\mathrm{T}_{1}\right)$ were determined from the 0-0 transitions of the low-temperature fluorescence spectra (Table 1). The differences between the secondary and tertiary amide-linked antennae are small. The former are lower in energy, but only by $100-300 \mathrm{~cm}^{-1}$. Oxygen sensitivity due to

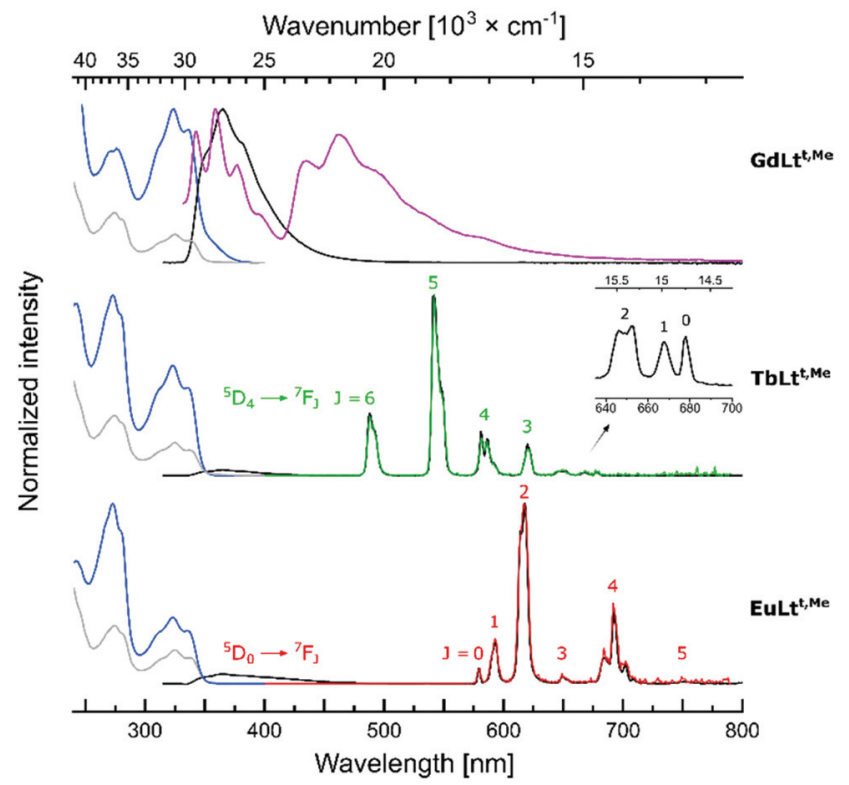

Fig. 4 Normalised absorption (left, grey). Excitation [left, blue, $\lambda_{\mathrm{em}}=$ $405 \mathrm{~nm}(\mathrm{Gd}), \lambda_{\mathrm{em}}=542 \mathrm{~nm}(\mathrm{~Tb}), \lambda_{\mathrm{em}}=618 \mathrm{~nm}(\mathrm{Eu}), 298 \mathrm{~K}$, steady-state emission (middle, black, $\lambda_{\mathrm{ex}}=325 \mathrm{~nm}, 298 \mathrm{~K}$ ), steady-state emission [middle, purple, $\lambda_{\mathrm{ex}}=325 \mathrm{~nm}(\mathrm{Gd}), 77 \mathrm{~K}$ ] and time-resolved emission (right, green (Tb), red (Eu), $\lambda_{\mathrm{ex}}=325 \mathrm{~nm}$ ) spectra of LnLt ${ }^{\mathrm{t}, \mathrm{Me}}$ complexes.

Table 1 Antenna photophysical properties of $\operatorname{LnLt}^{\mathrm{s}, \mathrm{R}}$ and $\mathrm{LnLt}^{\mathrm{t}, \mathrm{Ra}}$

\begin{tabular}{lllll}
\hline Compound & $\lambda_{\max }[\mathrm{nm}]$ & $\lambda_{\mathrm{em}}{ }^{b}[\mathrm{~nm}]$ & $E_{\text {0o }}\left(\mathrm{S}_{1}\right)^{c}\left[\mathrm{~cm}^{-1}\right]$ & $E_{00}\left(\mathrm{~T}_{1}\right)^{c}\left[\mathrm{~cm}^{-1}\right]$ \\
\hline GdLt $^{\mathbf{s}, \mathbf{M e}}$ & 329 & 366 & 28900 & 22900 \\
GdLt $^{\mathbf{t}, \mathbf{M e}}$ & 325 & 365 & 29200 & 23000 \\
GdLt $^{\mathbf{s}, \mathbf{M O M}}$ & 331 & 376 & 28500 & 22500 \\
GdLt $^{\mathbf{t}, \mathbf{M O M}}$ & 328 & 375 & 28900 & 22800 \\
GdLt $^{\mathbf{s}, \mathbf{C F 3}}$ & 342 & 391 & 27400 & 21700 \\
GdLt $^{\mathbf{t}}$,CF3 & 338 & 391 & 27500 & 22000
\end{tabular}

${ }^{a}$ In aqueous PIPES buffer $(10 \mathrm{mM}), \mathrm{pH} 6.5$, at $10 \mu \mathrm{M}$ complex concentrations. ${ }^{b} \lambda_{\mathrm{ex}}=329 \mathrm{~nm}\left(\mathbf{G d L t}^{\mathbf{s}, \mathbf{M e}}\right), 325 \mathrm{~nm}\left(\mathbf{G d L t}^{\mathbf{t}, \mathbf{M e}}\right), 335 \mathrm{~nm}$ $\left(\mathbf{G d L t}^{\mathbf{s}, \mathbf{M O M}}\right), 328 \mathrm{~nm}\left(\mathbf{G d L t}^{\mathbf{t}, \mathbf{M O M}}\right), 331 \mathrm{~nm}\left(\mathbf{G d L t}^{\mathbf{s}, \mathbf{C F} 3}\right), 330 \mathrm{~nm}$ $\left(\mathbf{G d L t}^{\mathbf{t}, \mathbf{C F} 3}\right) .{ }^{c}$ Calculated from the 0-0 transitions of the Gd-complexes recorded at $77 \mathrm{~K}$.

back energy transfer (BET) was previously seen in $\mathbf{L n L t} \mathbf{t}^{\mathbf{s , C F 3}} .^{42}$ To avoid BET the antenna $\mathrm{T}_{1}$ should be at least $2000 \mathrm{~cm}^{-1}$ above the $\mathrm{Tb}(\mathrm{III})$ excited state $\left(20400 \mathrm{~cm}^{-1}\right) .{ }^{32,47}$ The $300 \mathrm{~cm}^{-1}$ increase in $\mathrm{T}_{1}$ energy to $22000 \mathrm{~cm}^{-1}$ in $\mathbf{L n L t} \mathbf{t}^{\mathrm{t}, \mathbf{C F} 3}$ is probably not sufficient to prevent BET.

Emission spectra were collected with $\lambda_{\text {ex }}>325 \mathrm{~nm}$ to avoid excitation of the pyridines. Antenna excitation yielded $\mathrm{Tb}$ (III) and $\mathrm{Eu}(\mathrm{III})$ emission from all the complexes. Spectral shapes and the ratios of peak intensities were similar in $\mathbf{L n} \mathbf{L} \mathbf{t}^{\mathbf{s}, \mathbf{R}}$ and $\mathbf{L n L t}^{\mathbf{t}, \mathbf{R}}$, but differed from those observed in cyclen-based

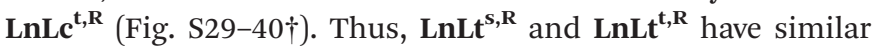
coordination environments, which differ from that created by the DO3A-type ligands. As in the cyclen-based systems, ${ }^{42}$ the influence of the linkers on the coordination geometry is negligible. The $\mathrm{Tb}$ (III) and Eu(III) spectra consisted of 6 and 5 major 
signals corresponding to the ${ }^{5} \mathrm{D}_{4} \rightarrow{ }^{7} \mathrm{~F}_{J}(J=6-0)$ the ${ }^{5} \mathrm{D}_{0} \rightarrow{ }^{7} \mathrm{~F}_{J}$ $(J=0-5)$ transitions, located at 488, 543, 582, 620, 652, 668, and $678 \mathrm{~nm}$, and at 579, 593, 614, 649, 693, and $751 \mathrm{~nm}$, respectively (Fig. 4).

The antenna and Ln(III)-based luminescence quantum yields ( $\Phi_{\mathrm{L}}$ and $\Phi_{\mathrm{Ln}}$, respectively) were determined by the optically dilute method using quinine sulfate (QS, $\Phi=0.59)^{48}$ as the external standard (Table 2). Gratifyingly, $\Phi_{\text {Ln }}$ obtained for the current series of $\mathrm{Eu}(\mathrm{III})$ and $\mathrm{Tb}(\mathrm{III})$ emitters ( $\mathbf{L} \mathbf{n} \mathbf{L t} \mathbf{t}^{\mathbf{t}, \mathbf{R}}$ ) were comparable to the high values previously obtained for the tertamide-linked DO3A-based species (LnLc ${ }^{\mathbf{t}, \mathbf{R}}$ ), a major improvement over the weak emission of $\mathbf{L n L} \mathbf{t}^{\mathbf{s}, \mathbf{R}}$. The highest $\Phi_{\mathrm{Tb}}$ and $\Phi_{\text {Eu }}$ were measured for TbLt $^{\mathbf{t}, \mathbf{M O M}}(42 \%)$ and EuLt ${ }^{\mathbf{t}, \mathbf{C F} 3}(13 \%)$, respectively. As before, $\Phi_{\mathrm{L}}$ were low, below $7 \%$ in all cases. Intriguingly, there was no discernable pattern as to the order of $\Phi_{\mathrm{L}}$ in the different ligand frameworks. In the non-photoactive and non-redox-active Gd(III) species, $\Phi_{\mathrm{L}}$ decreases as follows: $\mathbf{L c}^{\mathbf{t}, \mathbf{M e}}>\mathbf{L t}^{\mathrm{t}, \mathbf{M e}}>\mathbf{L t}^{\mathrm{s}, \mathbf{M e}}, \mathbf{L t}^{\mathrm{s}, \mathbf{M O M}}>\mathbf{L} \mathbf{c}^{\mathrm{t}, \mathbf{M O M}} \approx \mathbf{L t}^{\mathrm{t}, \mathbf{M O M}}$, and $\mathbf{L t}^{\mathbf{s , C F 3}}>\mathbf{L t} \mathbf{t}^{\mathrm{t}, \mathbf{C F} 3} \approx \mathbf{L} \mathbf{c}^{\mathrm{t}, \mathbf{C F} 3}$.

PeT from the antenna to the pyridines and to $\mathrm{Eu}(\mathrm{III})$ was calculated to be thermodynamically feasible (eqn (2)). Cyclic voltammetry yielded $E_{\mathrm{Ox}}$, the electron donor oxidation potential, as $+1.91,+1.94$, and $+2.20 \mathrm{~V}$ (vs. NHE) for the antenna models 5a-c (Scheme 1, Fig. S19-21†), respectively. These models were prepared to enable cyclic voltammetric analysis of the anten-

Table 2 Antenna- and metal-based luminescence quantum yields of LnLt ${ }^{t, R}$, with comparisons to $\operatorname{LnLt}^{\mathrm{s}, \mathrm{R}}$ (Ref. 38) and LnLc ${ }^{\mathrm{t}, \mathrm{R}}$ (Ref. 42). The values in parentheses show the change compared to $\operatorname{LnLc}^{\mathrm{t}, R}$

\begin{tabular}{|c|c|c|}
\hline Complex & $\Phi_{\mathrm{L}}[\%]^{a}$ & $\Phi_{\mathrm{Ln}}[\%]^{a}$ \\
\hline $\mathbf{G d L t}^{\mathbf{s}, \mathbf{M e} b}$ & $4.40 \pm 0.10(63 \%)$ & - \\
\hline $\mathbf{G d L t}^{\mathbf{t}, \mathbf{M e} b}$ & $5.47 \pm 0.07(79 \%)$ & - \\
\hline $\mathrm{GdLc}^{\mathrm{t}, \mathrm{Me}}$ & $6.8(100 \%)$ & - \\
\hline $\mathbf{G d L t}^{\mathbf{s}, \mathbf{M O M} b}$ & $6.42 \pm 0.28(131 \%)$ & - \\
\hline $\mathbf{G d L t}^{\mathbf{t}, \text { МОМ } b}$ & $4.94 \pm 0.06(98 \%)$ & - \\
\hline GdLe $^{\text {t,MOM }}$ & $5.1(100 \%)$ & - \\
\hline $\mathbf{G d L t}^{\mathbf{s}, \mathbf{C F} 3 b}$ & $4.53 \pm 0.17(147 \%)$ & - \\
\hline $\mathbf{G d L t}^{\mathbf{t}, \mathbf{C F 3} b}$ & $3.62 \pm 0.02(113 \%)$ & - \\
\hline GdLe $c^{t, C F 3}$ & $3.2(100 \%)$ & - \\
\hline $\mathbf{T b L t}^{\mathbf{s}, \mathbf{M e} b}$ & $3.50 \pm 0.10(58 \%)$ & $27.05 \pm 1.05(60 \%)$ \\
\hline TbLt $^{\text {t,Me } b}$ & $4.59 \pm 0.10(76 \%)$ & $40.4 \pm 0.40(93 \%)$ \\
\hline TbLc ${ }^{t, M e}$ & $5.9(100 \%)$ & $43.4(100 \%)$ \\
\hline TbLtt $^{\text {s,MOM } b}$ & $4.92 \pm 0.01(109 \%)$ & $28.05 \pm 0.95(64 \%)$ \\
\hline $\mathbf{T b L t}^{\mathbf{t}, \mathbf{M O M} b}$ & $4.28 \pm 0.03(96 \%)$ & $41.5 \pm 0.50(93 \%)$ \\
\hline TbLc ${ }^{t, M O M}$ & $4.5(100 \%)$ & $45.1(100 \%)$ \\
\hline $\mathbf{T b L t}^{\mathbf{s , C F 3} b}$ & $4.16 \pm 0.24(142 \%)$ & $3.24 \pm 0.14(19 \%)$ \\
\hline $\mathbf{T b L t}^{\mathbf{t , C F} b}$ & $3.33 \pm 0.28(116 \%)$ & $19.0 \pm 1.05(113 \%)$ \\
\hline TbLe $c^{t, M F 3}$ & $3.1(100 \%)$ & $15.9(100 \%)$ \\
\hline $\mathbf{E u L t}^{\mathbf{s}, \mathbf{M e} c}$ & $0.42 \pm 0.03(29 \%)$ & $0.83 \pm 0.02(14 \%)$ \\
\hline EuLt ${ }^{\mathbf{t}, \mathbf{M e} c}$ & $0.96 \pm 0.24(87 \%)$ & $3.45 \pm 1.10(83 \%)$ \\
\hline EuLc $c^{t, M e}$ & $1.5(100 \%)$ & $6.0(100 \%)$ \\
\hline $\mathbf{E u L t}^{\mathbf{s}, \mathbf{M O M} c}$ & $0.16 \pm 0.01(6 \%)$ & $2.44 \pm 0.07(28 \%)$ \\
\hline $\mathbf{E u L t}^{\mathrm{t}, \mathbf{M O M} c}$ & $1.32 \pm 0.06(52 \%)$ & $5.22 \pm 0.15(61 \%)$ \\
\hline EuLc ${ }^{t, M O M}$ & $2.5(100 \%)$ & $8.9(100 \%)$ \\
\hline EuLt $^{\text {s,CF3 } c}$ & $0.61 \pm 0.02(23 \%)$ & $7.95 \pm 0.42(68 \%)$ \\
\hline $\mathbf{E u L t}^{\mathrm{t}, \mathrm{CF} 3 c}$ & $2.81 \pm 0.08(100 \%)$ & $13.0 \pm 0.10(108 \%)$ \\
\hline EuLc $c^{t, C F 3}$ & $2.7(100 \%)$ & $11.6(100 \%)$ \\
\hline
\end{tabular}

${ }^{a}$ Relative to QS $(\Phi=0.59)$ in $\mathrm{H}_{2} \mathrm{SO}_{4}(0.05 \mathrm{M}) .{ }^{48}{ }^{b}$ Mean \pm standard deviation for two independent measurements. ${ }^{c}$ Mean \pm standard deviation for three independent measurements. nae without interference from the other redox-active components of the complexes. $E_{\text {red }}$ is the electron acceptor reduction potential. Pyridine $E_{\text {red }}(-1.29 \mathrm{~V} v s$. NHE) has been reported; ${ }^{38} E_{\text {red }}$ of $\mathrm{Eu(III)}$ was approximated with values found for a +1 charged cyclen-based complex $(-0.80 \mathrm{~V} v s$. NHE for a MOM-substituted complex). ${ }^{40}$ This was necessary as the presence of the pyridines, which are reduced at similar potentials make Eu(III) $E_{\text {red }}$ determination unreliable in this ligand framework. $E_{\mathrm{S}}$ is the antenna excited state energy, determined from the first vibronic band of the $77 \mathrm{~K}$ spectra as $3.60,3.57$, and $3.39 \mathrm{eV}$ for $\mathbf{G d L t}^{\mathbf{t}, \mathbf{M e}}, \mathbf{G d L t}^{\mathbf{t}, \mathbf{M O M}}$, and $\mathbf{G d L t}^{\mathbf{t}, \mathbf{C F} 3}$ respectively. The last term is the coulombic stabilization of the charge-separated system, usually taken as $\sim 0.15 \mathrm{eV} .^{49}$

$$
\Delta G=\left(E_{\text {ox }}-E_{\text {red }}\right)-E_{\mathrm{S}}-\frac{e_{0}^{2}}{\varepsilon r}
$$

$\Delta G$ for PeT from the $\mathrm{CF}_{3}$-substituted antenna to the pyridine was $-0.54 \mathrm{eV}$. Values for the more electron-rich antennae were more negative, $-0.98 \mathrm{eV}$ and $-1.04 \mathrm{eV}$ for the MOM- and Me-substituted ones, respectively. Eu(III) reduction was even more favorable, with $\Delta G$ values of $-0.95,-0.87$, and $-0.45 \mathrm{eV}$, for Me-, MOM- and $\mathrm{CF}_{3}$-substituted complexes, respectively. In DO3A-complexes, sec-amide-linked antennae are more fluorescent than the tert-amide-linked ones. ${ }^{42}$ The overall $\Phi_{\mathrm{L}}$ order is the result of the combination of these effects. In the $\mathrm{Tb}$ (III) and $\mathrm{Eu}(\mathrm{III})$ complexes the situation is further complicated by the photo- and, in the case of $\mathrm{Eu}(\mathrm{III})$, redox-activity of the metals.

The number of metal-coordinated water molecules $(q)$ were determined from $\tau_{\text {obs }}$ of $\mathrm{Eu}(\mathrm{III})$ and $\mathrm{Tb}(\mathrm{III})$ (Table 3). ${ }^{3,35}$ The luminescence decays were monoexponential for these complexes, with $\tau_{\text {obs }}=\sim 0.52 \mathrm{~ms}$ and $\sim 1.34 \mathrm{~ms}$ for EuL and TbL, respectively. In all cases $q$ was $\sim 1$, which together with the octadentate ligand gives the expected nine-coordinate complexes. BET in $\mathbf{T b L t}^{\mathbf{t}, \mathbf{C F 3}}$ did not allow for the determination of $q$, however, it is most likely 1 by analogy with the other complexes.

The similar $\Phi_{\mathrm{L}}$ and $\Phi_{\mathrm{Ln}}$ values of pyridine-equipped $\mathbf{L} \mathbf{L} \mathbf{L} \mathbf{t}^{\mathbf{t}, \mathbf{R}}$ and DO3A-based $\mathbf{L n L} \mathbf{c}^{\mathbf{t}, \mathbf{R}}$ suggested that either PeT to the pyridines was less efficient in $\mathbf{L n} \mathbf{L t}{ }^{\mathbf{t}, \mathbf{R}}$ than in $\mathbf{L n L t}^{\mathbf{s}, \mathbf{R}}$, or PET was

Table $3 \operatorname{Ln}\left(\right.$ III) $\tau_{\text {obs }}$ and $q$-values in EuLt ${ }^{\mathrm{t}, \mathrm{R}}$ and TbLt ${ }^{\mathrm{t}, \mathrm{Ra}}$

\begin{tabular}{|c|c|c|c|}
\hline Complex & $\tau_{\mathrm{H}_{2} \mathrm{O}}[\mathrm{ms}]$ & $\tau_{\mathrm{D}_{2} \mathrm{O}}[\mathrm{ms}]$ & $q^{b}$ \\
\hline TbLt $^{t, M e}$ & 1.37 & 2.13 & 0.99 \\
\hline EuLt ${ }^{t, M e}$ & 0.51 & 1.43 & 1.18 \\
\hline $\mathrm{TbLt}^{\mathrm{t}, \mathrm{MOM}}$ & 1.30 & 2.01 & 1.06 \\
\hline EuLt $^{t, M O M}$ & 0.52 & 1.43 & 1.15 \\
\hline TbLt $^{\mathrm{t}, \mathrm{CF} 3}$ & 0.62 & 1.01 & $2.71^{c}$ \\
\hline $\mathrm{EuLt}^{\mathrm{t}, \mathrm{CF} 3}$ & 0.52 & 1.43 & 1.15 \\
\hline
\end{tabular}

${ }^{a}$ Recorded in PIPES-buffered $\mathrm{H}_{2} \mathrm{O}$ or $\mathrm{D}_{2} \mathrm{O}$ solutions at $\mathrm{pH}=6.5$ at room temperature. ${ }^{b}$ Calculated using $q=(5 \mathrm{~ms})\left(1 / \tau_{\mathrm{H}_{2} \mathrm{O}}-1 / \tau_{\mathrm{D}_{2} \mathrm{O}}-\right.$ $\left.0.06 \mathrm{~ms}^{-1}\right)$ for $\mathrm{Tb}$, and $q=(1.2 \mathrm{~ms})\left(1 / \tau_{\mathrm{H}_{2} \mathrm{O}}-1 / \tau_{\mathrm{D}_{2} \mathrm{O}}-0.25 \mathrm{~ms}^{-1}-m\right.$ $0.075 \mathrm{~ms}^{-1}$ ) for Eu; $m=$ number of nearby amide $\mathrm{N}-\mathrm{H}$ oscillators. ${ }^{3,35}$ ${ }^{c}$ Real $q$ value could not be determined. 
successfully outcompeted by energy transfer to the Ln(III). The efficiency with which the antenna excited state populates the Ln(III) excited state $\left(\eta_{\text {sens }}\right)$ is readily calculated for Eu(III) emitters using eqn (1) and (3) (Table 4). ${ }^{36,37}$ Antenna excited state quenching affects $\eta_{\text {sens }}$. If complexes with identical antennae and similar geometries have different $\eta_{\text {sens }}$, this difference may be due to differences in PeT. $\Phi_{\mathrm{Ln}}^{\mathrm{Ln}}$ in eqn (1) can be calculated ${ }^{36}$ from $\tau_{\text {rad }}$ of $\mathrm{Eu}(\mathrm{III})$, which is obtained from the luminescence spectrum using eqn (3). $I_{\text {tot }}$ is the integrated full spectrum (530-800 nm), $I_{\mathrm{MD}}$ is the integrated ${ }^{5} \mathrm{D}_{0} \rightarrow{ }^{7} \mathrm{~F}_{1}$ transition (582-603 nm), $A_{M D, 0}$ is the spontaneous emission probability $\left(14.65 \mathrm{~s}^{-1}\right), n$ is the refractive index of the aqueous medium (approximated with water), and $\tau_{\mathrm{obs}}$ equals $\tau_{\mathrm{H}_{2} \mathrm{O}}$.

$$
\frac{1}{\tau_{\mathrm{rad}}}=A_{\mathrm{MD}, 0} \cdot n^{3}\left(\frac{I_{\mathrm{tot}}}{I_{\mathrm{MD}}}\right)
$$

$\mathbf{E u L t}^{\mathbf{t}, \mathbf{R}}$ and $\mathbf{E u L t} \mathbf{t}^{\mathbf{s}, \mathbf{R}}$ have similar $\tau_{\text {rad }}(\sim 2.9 \mathrm{~ms})$. This is in line with their having similar Ln(III) coordination environments, as suggested by their superimposable luminescence spectra (Fig. S53-55†). The slightly longer $\tau_{\text {obs }}$ of EuLt ${ }^{\mathbf{t}, \mathbf{R}}$ than of $\mathbf{E u L t}^{\mathbf{s}, \mathbf{R}}$ is presumably due to the removal of the $\mathrm{N}-\mathrm{H}$ group from the amide linker. Overall, the effect of the tertiary amides on $\Phi_{\mathrm{Ln}}^{\mathrm{Ln}}$ is small compared to $\mathbf{E u L t}^{\mathbf{s}, \mathbf{R}}$, and all complexes have $\Phi_{\mathrm{Ln}}^{\mathrm{Ln}} \sim 17.5 \%$. Compared with the $\Phi_{\mathrm{Ln}}^{\mathrm{Ln}} \sim 12 \%$ obtained for EuLc ${ }^{\mathbf{t}, \mathbf{R}}$, this is a significant improvement. The shortening of $\tau_{\text {rad }}$ to increase $\Phi_{\mathrm{Ln}}^{\mathrm{Ln}}$ is a rarely used strategy for improving $\Phi_{\mathrm{Ln}} \cdot{ }^{50}$

Although EuLt ${ }^{\mathbf{t}, \mathbf{R}}$ have higher $\Phi_{\mathrm{Ln}}^{\mathrm{Ln}}$ than EuLc ${ }^{\mathbf{t}, \mathbf{R}}$ their $\Phi_{\mathrm{Ln}}$ values were similar or lower, due to the lower $\eta_{\text {sens. }}$ EuLt ${ }^{\mathbf{t}, \mathbf{R}}$ shows marked improvement in $\eta_{\text {sens }}$ compared to secondary amide-linked EuLt ${ }^{\mathbf{s}, \mathbf{R}}$ (e.g. $28 \%$ and $5 \%$ in $\mathbf{E u L t}^{\mathbf{t}, \mathbf{M e}}$ and EuLt $^{\text {s,Me }}$, respectively), just not enough to reach the values seen in $\mathbf{E u L c}^{\mathbf{t}, \mathbf{R}}\left(50 \%\right.$ in EuLc $\left.\mathbf{c}^{\mathbf{t}, \mathbf{M e}}\right)$. The better sensitization in $\mathbf{E u L t}^{\mathbf{t}, \mathbf{R}}$ than in $\mathbf{E u L t}^{\mathbf{s}, \mathbf{R}}$ may be due to less efficient PeT to the pyridines. This is suggested by the fact that $\Phi_{\mathrm{L}}$ in $\mathbf{G d L t}^{\mathbf{t}}$,Me somewhat higher than in $\mathbf{G d L t}^{\mathbf{s}, \mathbf{M e}}$ even though in DO3A-based complexes secondary amide linked antennae have higher $\Phi_{\mathrm{L}}$ than their tertiary amide-linked analogues. ${ }^{42}$ However, the low $\Phi_{\mathrm{L}}$ values do not allow for a reliable comparison. A second alternative explanation for the observed results may be more efficient energy transfer due to a different antenna orientation. A third possibility is more efficient population of the $\operatorname{Ln}(\mathrm{III})$

Table $4 \tau_{\text {rad }}, \Phi_{\mathrm{Ln}}^{\mathrm{Ln}}$, and $\eta_{\text {sens }}$ of EuL

\begin{tabular}{|c|c|c|c|}
\hline Complex & $\tau_{\mathrm{rad}}{ }^{a}[\mathrm{~ms}]$ & $\Phi_{\mathrm{Eu}}{ }^{\mathrm{Eu} b}[\%]$ & $\eta_{\text {sens }}{ }^{b}[\%]$ \\
\hline EuLt $^{\text {s,Me }}$ & 2.87 & 17.4 & 5 \\
\hline $\operatorname{EuLt}^{t, M e}$ & 2.94 & 17.7 & 28 \\
\hline EuLc ${ }^{t, M e}$ & 5.41 & 12.0 & 50 \\
\hline $\mathrm{EuLt}^{\mathrm{s}, \mathrm{MOM}}$ & 2.86 & 17.5 & 14 \\
\hline $\mathrm{EuLt}^{\mathrm{t}, \mathrm{MOM}}$ & 2.96 & 17.9 & 30 \\
\hline EuLc $c^{t, M O M}$ & 5.40 & 12.2 & 73 \\
\hline $\mathrm{EuLt}^{\mathrm{s}, \mathrm{CF} 3}$ & 2.87 & 17.8 & 46 \\
\hline $\mathrm{EuLt}^{\mathrm{t}, \mathrm{CF} 3}$ & 2.99 & 17.4 & 75 \\
\hline EuLc $c^{t, C F 3}$ & 5.40 & 12.2 & 95 \\
\hline
\end{tabular}

${ }^{a}$ Calculated using eqn (3). ${ }^{36}$ Calculated using eqn (1) and (3). ${ }^{36}$ feeding level, likely the antenna $\mathrm{T}_{1}$, due to more efficient intersystem crossing in $\mathbf{L} \mathbf{L} \mathbf{t}^{\mathbf{t}, \mathbf{R}}$ than in $\mathbf{L} \mathbf{n} \mathbf{L t} \mathbf{t}^{\mathbf{s}, \mathbf{R}}$. The additional

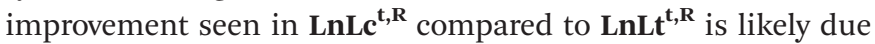
to the absence of PeT to pyridines. As above, antenna orien-

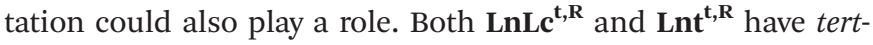
amide-linked antennae, and the similar values of $\Phi_{\mathrm{L}}$ are consistent with comparable levels of antenna $S_{1}$ quenching. Thus the higher $\eta_{\text {sens }}$ in cyclen-based $\mathbf{L n L c ^ { \mathbf { t } , \mathbf { R } }}$ indicates more efficient energy transfer than in tacn-based $\mathbf{L n t}^{\mathbf{t}, \mathbf{R}}$.

Photostability of LnL. The photostability of a Ln(III) emitter is an important parameter for practical applications. Unlike those of organic fluorophores, Ln(III) excited states are not sensitive to quenching by atmospheric oxygen. ${ }^{51}$ Photodegradation is rather due to processes that compromise the integrity of the other functional units in the complex, often the antenna. BET from $\operatorname{Ln}(\mathrm{III})^{*}$ to the antenna $\mathrm{T}_{1}$ or slow energy transfer from $\mathrm{T}_{1}$ to $\mathrm{Ln}$ (III) caused by too small or too large $\mathrm{T}_{1}-\mathrm{Ln}(\mathrm{III})^{*}$ gaps, respectively, both result in long $\mathrm{T}_{1}$ lifetimes, and thus oxygen-sensitivity.

The photostabilities of the complexes reported herein $\left(\mathbf{L n} \mathbf{L} t^{\mathbf{t}, \mathbf{R}}\right)$ were investigated and compared to those of $\mathbf{L n} \mathbf{L} \mathbf{t}^{\mathbf{s}, \mathbf{R}}$

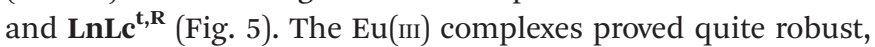
and retained at least $90 \%$ of their luminescence after $2.5 \mathrm{~h}$ of irradiation. Small differences, however, could be noted.
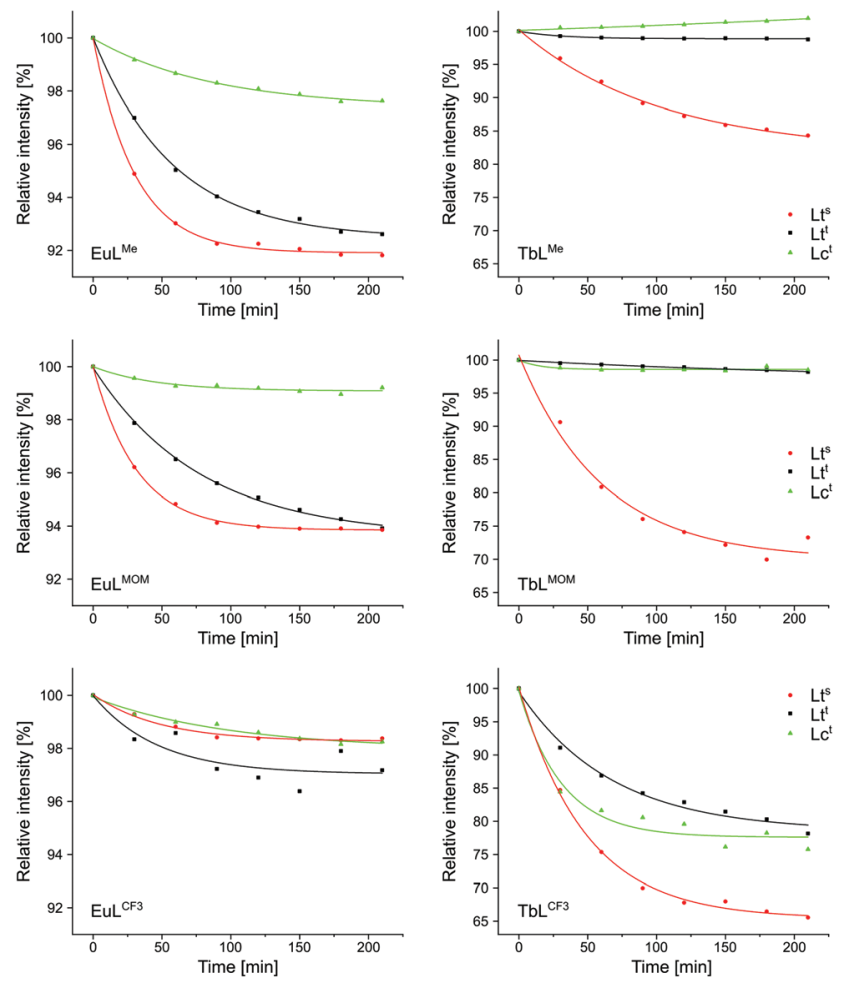

Fig. 5 Photostability of Tb and Eu complexes $(10 \mu \mathrm{M})$ in aqueous PIPES buffer $(10 \mathrm{mM}), \mathrm{pH}=6.5$, using $395 \mathrm{~nm}$ filter for $\mathrm{Tb}$ and $500 \mathrm{~nm}$ filter for Eu complexes, respectively. $\lambda_{\mathrm{ex}}\left(\operatorname{LnLc}^{\mathrm{t}, M e}\right)=324 \mathrm{~nm}, \lambda_{\mathrm{ex}}\left(\operatorname{LnLt}^{\mathrm{t}, M e}\right)=$ $325 \mathrm{~nm}, \lambda_{\mathrm{ex}}\left(\operatorname{LnLc}^{\mathrm{t}, \mathrm{MOM} / \mathrm{CF} 3}\right)=327 \mathrm{~nm}, \lambda_{\mathrm{ex}}\left(\operatorname{LnLt}^{\mathrm{s}, M e} / \operatorname{LnLt}^{\mathrm{t}, M O M}\right)=328 \mathrm{~nm}$, $\lambda_{\mathrm{ex}}\left(\operatorname{LnLt}^{\mathrm{s}, \mathrm{MOM}} /\left(\operatorname{LnLt}^{\mathrm{s}, \mathrm{CF} 3} / \operatorname{LnLt}^{\mathrm{t}, \mathrm{CF} 3}\right)=330 \mathrm{~nm}\right.$. Values normalised to integrated emission intensity at $t_{0}$. 
Complexes equipped with a $\mathrm{CF}_{3}$-substituted antenna were the most resistant to photodegradation, while the least stable were the ones carrying the most electron-rich Me-substituted antenna. Cyclen-based EuLc ${ }^{\mathbf{t}, \mathbf{R}}$ were in all cases more stable than their tacn-based analogues $\mathbf{E u L t}^{\mathbf{s}, \mathbf{R}}$ and $\mathbf{E u L t}^{\mathbf{t}, \mathbf{R}}$. Tertamide-linked $\mathbf{E u L t}^{\mathbf{t}, \mathbf{R}}$ were somewhat more stable then secamide-linked $\mathbf{E u L t}^{\mathbf{s}, \mathbf{R}}$. These trends are consistent with PeT opening up a degradation pathway for the complex. This pathway is more prominent for picolinate-carrying $\mathbf{E u L t}^{\mathbf{s}, \mathbf{R}}$ and EuLt $^{\mathbf{t}, \mathbf{R}}$, which contain both Eu(III) and pyridines as potential electron acceptors.

In the case of the $\mathrm{Tb}$ (III) complexes fastest degradation was seen for those with the lowest antenna $\mathrm{T}_{1}$. All three $\mathrm{CF}_{3}$-Substituted complexes rapidly lost $\mathrm{Tb}$ (III) luminescence efficiency. This loss was fastest for $\mathbf{T b L t} \mathbf{t}^{\mathbf{s}, \mathbf{C F} 3}$, with a sec-amide-linked antenna. For the other two antennae attaching them via a tertamide, and the concomitant increase in $\mathrm{T}_{1}$ was sufficient to protect the integrity of the emitters. These trends indicate that photolability is due to BET populating the antenna $T_{1}$, followed by $\mathrm{T}_{1}$ reacting with atmospheric oxygen.

\section{Conclusions}

We investigated the effect of replacing a secondary amide linker with a methylcarboxylate-substituted tertiary amide one on the photophysical properties of tacn-based luminescent Ln(III) complexes. In solution the amide substituent was noncoordinating, and did not alter the coordination geometry of the complex compared to the parent species. This was indicated by the shapes of the Ln(III) luminescence spectra and the radiative lifetimes of the Eu(III) complexes, and was supported by the results of the paramagnetic NMR spectroscopic and single crystal X-ray crystallographic analyses in the solution and solid states, respectively.

Changing the linker from secondary to tertiary amide had a profound effect on the $\mathrm{Eu}(\mathrm{III})$ and $\mathrm{Tb}$ (III) luminescence. In tacnbased, pyridine-containing Ln(III) complexes with secondary amide linkers pyridine reduction by the photoexcited carbostyril competed efficiently with Eu(III) and $\mathrm{Tb}(\mathrm{III})$ sensitization. Upon linker replacement all of the emitters experienced an increase in luminescence quantum yield, with values close to, and in some cases even higher than, those obtained for cyclenbased systems lacking the quenching pyridines. An additional benefit of the tert-amide linkers is higher antenna $\mathrm{T}_{1}$ energy, and thus decreased BET for Tb(III) emitters. Finally, tertiary amide linked complexes based on both tacn and cyclen frameworks showed high photostability, highlighting the importance of closing down PeT and BET quenching pathways to obtain robust emitters.

\section{Author contributions}

D. Kocsi and D. Kovacs: conceptualization, resources, investigation, data curation, visualization, formal analysis. J.A.L.W.: investigation, data curation, visualization, formal analysis. K.E. B.: conceptualization, funding acquisition, project administration, resources, formal analysis, visualization, supervision. All authors were involved in the writing of the original draft and took part in the reviewing and editing of the manuscript.

\section{Conflicts of interest}

There are no conflicts to declare.

\section{Acknowledgements}

This work was supported by the Swedish Research Council (project grant 2017-04077 for K.E.B.), the Knut och Alice Wallenbergs Foundation (Dnr: 2018.0066).

\section{Notes and references}

1 J.-C. G. Bünzli and S. V. Eliseeva, in Lanthanide Luminescence: Photophysical, Analytical and Biological Aspects, ed. P. Hänninen and H. Härmä, Springer Berlin Heidelberg, Berlin, Heidelberg, 2011, pp. 1-45.

2 A. de Bettencourt-Dias, in Luminescence of Lanthanide Ions in Coordination Compounds and Nanomaterials, John Wiley \& Sons Ltd, 2014, pp. 1-48.

3 W. D. Horrocks and D. R. Sudnick, Acc. Chem. Res., 1981, 14, 384-392.

4 W. D. Horrocks, Jr., J. P. Bolender, W. D. Smith and R. M. Supkowski, J. Am. Chem. Soc., 1997, 119, 5972-5973.

5 A. S. Chauvin, F. Gumy, D. Imbert and J. C. G. Bünzli, Spectrosc. Lett., 2004, 37, 517-532.

6 A. de Bettencourt-Dias, P. S. Barber and S. Bauer, J. Am. Chem. Soc., 2012, 134, 6987-6994.

7 A. de Bettencourt-Dias, S. Viswanathan and A. Rollett, J. Am. Chem. Soc., 2007, 129, 15436-15437.

8 J. H. S. K. Monteiro, A. de Bettencourt-Dias and F. A. Sigoli, Inorg. Chem., 2017, 56, 709-712.

9 R. Xiong, D. Mara, J. Liu, R. Van Deun and K. E. Borbas, J. Am. Chem. Soc., 2018, 140, 10975-10979.

10 J. Laakso, G. A. Rosser, C. Szíjjártó, A. Beeby and K. E. Borbas, Inorg. Chem., 2012, 51, 10366-10374.

11 T. Zhang, X. Zhu, C. C. W. Cheng, W.-M. Kwok, H.-L. Tam, J. Hao, D. W. J. Kwong, W.-K. Wong and K.-L. Wong, J. Am. Chem. Soc., 2011, 133, 20120-20122.

12 Y. Ning, M. Zhu and J.-L. Zhang, Coord. Chem. Rev., 2019, 399, 213028.

13 Y. Ning, G.-Q. Jin and J.-L. Zhang, Acc. Chem. Res., 2019, 52, 2620-2633.

14 Y. Ning, J. Tang, Y.-W. Liu, J. Jing, Y. Sun and J.-L. Zhang, Chem. Sci., 2018, 9, 3742-3753.

15 D. Parker, P. K. Senanayake and J. A. G. Williams, J. Chem. Soc., Perkin Trans. 2, 1998, 2129-2139.

16 A. Beeby, S. Faulkner, D. Parker and J. A. G. Williams, J. Chem. Soc., Perkin Trans. 2, 2001, 1268-1273. 
17 D. G. Smith, R. Pal and D. Parker, Chem. - Eur. J., 2012, 18, 11604-11613.

18 D. G. Smith, B. K. McMahon, R. Pal and D. Parker, Chem. Commun., 2012, 48, 8520-8522.

19 A. Foucault-Collet, C. M. Shade, I. Nazarenko, S. Petoud and S. V. Eliseeva, Angew. Chem., Int. Ed., 2014, 53, 2927-2930.

20 S. Petoud, G. Muller, E. G. Moore, J. Xu, J. Sokolnicki, J. P. Riehl, U. N. Le, S. M. Cohen and K. N. Raymond, J. Am. Chem. Soc., 2007, 129, 77-83.

21 S. Faulkner, M.-C. Carrie, S. J. A. Pope, J. Squire, A. Beeby and P. G. Sammes, Dalton Trans., 2004, 1405-1409.

22 C. Y. Chow, S. V. Eliseeva, E. R. Trivedi, T. N. Nguyen, J. W. Kampf, S. Petoud and V. L. Pecoraro, J. Am. Chem. Soc., 2016, 138, 5100-5109.

23 E. R. Trivedi, S. V. Eliseeva, J. Jankolovits, M. M. Olmstead, S. Petoud and V. L. Pecoraro, J. Am. Chem. Soc., 2014, 136, 1526-1534.

24 T. N. Nguyen, C. Y. Chow, S. V. Eliseeva, E. R. Trivedi, J. W. Kampf, I. Martinic, S. Petoud and V. L. Pecoraro, Chem. - Eur. J., 2018, 24, 1031-1035.

25 T. Lazarides, D. Sykes, S. Faulkner, A. Barbieri and M. D. Ward, Chem. - Eur. J., 2008, 14, 9389-9399.

26 T. Lazarides, N. M. Tart, D. Sykes, S. Faulkner, A. Barbieri and M. D. Ward, Dalton Trans., 2009, 3971-3979.

27 N. M. Shavaleev, L. P. Moorcraft, S. J. A. Pope, Z. R. Bell, S. Faulkner and M. D. Ward, Chem. Commun., 2003, 11341135.

28 N. M. Shavaleev, L. P. Moorcraft, S. J. A. Pope, Z. R. Bell, S. Faulkner and M. D. Ward, Chem. - Eur. J., 2003, 9, 52835291.

29 S. J. A. Pope, B. J. Coe and S. Faulkner, Chem. Commun., 2004, 1550-1551.

30 S. Faulkner and S. J. A. Pope, J. Am. Chem. Soc., 2003, 125, 10526-10527.

31 S. Cotton, in Lanthanide and Actinide Chemistry, 2006, pp. 35-60.

32 D. Parker, R. S. Dickins, H. Puschmann, C. Crossland and J. A. K. Howard, Chem. Rev., 2002, 102, 1977-2010.

33 W. D. Horrocks, Jr. and D. R. Sudnick, J. Am. Chem. Soc., 1979, 101, 334-340.
34 R. S. Dickins, D. Parker, A. S. de Sousa and J. A. G. Williams, Chem. Commun., 1996, 697-698.

35 A. Beeby, I. M. Clarkson, R. S. Dickins, S. Faulkner, D. Parker, L. Royle, S. A. S. de, J. A. G. Williams and M. Woods, J. Chem. Soc., Perkin Trans. 2, 1999, 493504.

36 M. H. V. Werts, R. T. F. Jukes and J. W. Verhoeven, Phys. Chem. Chem. Phys., 2002, 4, 1542-1548.

37 K. Binnemans, Coord. Chem. Rev., 2015, 295, 1-45.

38 D. Kovacs, D. Kocsi, J. A. L. Wells, S. R. Kiraev and K. E. Borbas, Dalton Trans., 2021, 50, 4244-4254.

39 D. Kovacs, S. R. Kiraev, D. Phipps, A. Orthaber and K. E. Borbas, Inorg. Chem., 2020, 59, 106-117.

40 D. Kovacs, E. Mathieu, S. R. Kiraev, J. A. L. Wells, E. Demeyere, A. Sipos and K. E. Borbas, J. Am. Chem. Soc., 2020, 142, 13190-13200.

41 S. R. Kiraev, E. Mathieu, F. Siemens, D. Kovacs, E. Demeyere and K. E. Borbas, Molecules, 2020, 25, 5282.

42 D. Kovacs, D. Phipps, A. Orthaber and K. E. Borbas, Dalton Trans., 2018, 47, 10702-10714.

43 D. Parker and J. A. G. Williams, J. Chem. Soc., Perkin Trans. 2, 1996, 1581-1586.

44 D. Kovacs and K. E. Borbas, Coord. Chem. Rev., 2018, 364, 1-9.

45 A. K. R. Junker and T. J. Sorensen, Eur. J. Inorg. Chem., 2019, 2019, 1201-1206.

46 L.-M. Fu, X.-C. Ai, M.-Y. Li, X.-F. Wen, R. Hao, Y.-S. Wu, Y. Wang and J.-P. Zhang, J. Phys. Chem. A, 2010, 114, 44944500.

47 J.-C. G. Bunzli, Coord. Chem. Rev., 2015, 293-294, 19-47.

48 K. Suzuki, A. Kobayashi, S. Kaneko, K. Takehira, T. Yoshihara, H. Ishida, Y. Shiina, S. Oishi and S. Tobita, Phys. Chem. Chem. Phys., 2009, 11, 9850-9860.

49 A. Beeby, S. Faulkner and J. A. G. Williams, J. Chem. Soc., Dalton Trans., 2002, 1918-1922.

50 S. V. Eliseeva, D. N. Pleshkov, K. A. Lyssenko, L. S. Lepnev, J.-C. G. Bunzli and N. P. Kuzmina, Inorg. Chem., 2011, 50, 5137-5144.

51 A. Beeby, D. Parker and J. A. G. Williams, J. Chem. Soc., Perkin Trans. 2, 1996, 1565-1580. 